\title{
REPORT OF THE SECRETARY TO THE COUNCIL FOR THE YEARS 1921-1925
}

The following is a brief report on the campaign to increase the effectiveness of the Society and on other outstanding mathematical events of the last five years, together with an attempt to set forth some of the possibilities for the future.

STATUS OF THE AMERICAN MATHEMATICAL SOCIETY IN 1921

In a quarter-century the Society had grown from a mere handful of mathematicians to a powerful organization of about 750 members, covering the United States and Canada. The faith and courage of its founders had been amply justified in the rise of American mathematics from a place among the beginners in research to one among the leading nations. No matter how much may be accomplished in the second quarter-century, progress cannot be expected to compare with that of such a dramatic period. The founding and support of two important journals and the establishment of the Colloquium Lectures were scientific events of the first importance. But the war had checked the growth of the Society and had raised ominous questions. Printing costs were soaring; the government, the industries, insurance, and the banks were drawing off some of the more promising of the younger well-trained mathematicians. The universities, struggling with greatly increased enrollments and hampered by depreciation of endowments, were calling on their faculties for increased hours of teaching.

\section{EFFORTS TO OVERCOME FINANCIAL DIFFICULTIES}

While the war had not been as disastrous to scientific endeavor in America as in many of the other countries involved, it left behind it acute problems. Since nearly the whole income of the Society is devoted to printing, the trebling of that cost seemed almost to spell disaster. The survival of the Transactions was in question and a radical 
reduction in the size of the BuLLETIN seemed inevitable. It was vital that the financial problems be attacked vigorously.

One of the obvious methods of increasing the income was to enlarge the membership: for three successive years successive committees on membership, under the leadership of Professor Hedrick, President Bliss, and Professor Cohen, did noteworthy service in enlarging the membership and since that time the campaign has been continued with the aid of the permanent secretary of the membership committee. Each year about two hundred members have been added, the total of those elected in the five years being now in excess of eleven hundred, the accessions including distinguished scientists from-abroad as well as many leading actuaries, engineers, and physicists on this side of the water.

The increase in income arising from increased membership proved, however, inadequate to the situation. To add to our difficulties, the nation-wide strike of type-setters had delayed printing. When late in 1922 it was again possible to proceed with printing in somewhat normal fashion, the accumulation of papers for the TRANSACTIONs together with the financial stringency was dismaying. There were several special gifts to the Society, but it was the anonymous gift of $\$ 4,000$ through Professor Huntington for an extra volume of the Transactions that put heart into those responsible for the Society's policy at that time.

It had been expected that printing costs would recede after the war, but by the end of 1922 it was apparent that this was not to be the case. If the Society was to move forward, it was evident that, besides the measures already taken, economies must be effected and permanent funds raised for support of its activities. As a temporary expedient it was decided to transfer the printing of the journals to Hamburg in order to cut down expense. At the Annual Meeting of 1922 in order to grapple further with the financial problems a Committee on Endowment was authorized. By the spring of 1923 this committee, under the chairmanship of Professor 
Coolidge, had been appointed by President Veblen and, having collected five thousand dollars for an expense account, was at work on a campaign to raise one hundred thousand dollars endowment. By effective and devoted effort on their part and that of the President, this campaign was crowned with success.

Members of the Society contributed about $\$ 25,000$ to this fund and others interested in mathematics added about $\$ 30,000$. To supplement this and to ensure an income at least equal to that which would be obtained from the amount set as a goal, the Committee procured some thirty-seven sustaining members, the annual subscriptions ranging from $\$ 100$ to $\$ 500$. If this membership can be kept near its present level, the Society is in a financial condition even more favorable than if the sum originally named had been procured for the treasury. In order to bring this about a new committee with Professor Fort at its head has been formed.

While the endowment campaign may be considered a complete success in attaining its goal, the Society still has serious financial problems. To meet the immediate needs, the National Academy of Sciences has recently appropriated for the year 1925-26 the sum of $\$ 3100$ from funds provided by the General Education Board to be applied to defraying the extra cost of printing the journals in this country. It is hoped that this subvention can be continued.*

\section{CHANGES IN ORGANIZATION}

After attempts at some form of incorporation extending over several years, the Society was finally incorporated in the District of Columbia during the year 1923 and is now in a position to receive gifts and bequests and to administer trust funds. No radical changes in organization were necessitated by this move. The Board of Trustees which, according to the law of the District, has charge of business ar-

* An appropriation for the year 1926-27 has been authorized since this Report was written. 
rangements, serves in a capacity much like a financial committee of the Council.

The mid-western group formerly known as the Chicago Section has been more closely merged into the organization, all its meetings being coordinate with those of the Society proper. The San Francisco Section has extended its domain and holds one meeting annually in the north-west.

\section{REGULAR ACTIVITIES}

In 1920 the budget was approximately eight thousand dollars, while in 1926 it is expected that the expenditures will be about twenty-four thousand. The activities of the Society have not increased in any such ratio, but it may be fair to estimate that they have increased by at least a quarter in the same period.

The Society exists primarily for the encouragement, presentation, and publication of mathematical research, and it is on this basis that progress must be measured. Both the Bulletin and Transactions have been enlarged twenty per cent and their facilities are now taxed to the utmost. The editors are rendering remarkable service too little realized by the membership in general. The number of papers read at the meetings and the attendance have increased by more than twenty per cent. The custom of having at meetings of the Society expository papers of an hour duration and given by request, has been greatly extended and the publication of these reports in the Bulletin has enriched the literature in several fields. The library of the Society has enjoyed steady growth and a catalogue has been issued; members are invited to make free use of the fine collection of journals.

There has been one Colloquium held during this period; funds are available for publishing these lectures and also those of the 1920 Colloquium still unprinted. It is confidently expected that more frequent Colloquia will be possible in the future. 


\section{NEW DEPARTURES}

Three Prize Funds. During this period the Bôcher Fund has been turned over to the Society and the two occasions of presentation of prizes in 1923 and 1924 have been notable events in our history. It has been arranged also to make within three years the first award of the prize from the Cole Fund. The Moore Fund has been raised and made available for publication and prizes.

Gibbs Lectureship. In order to present to the educated public some of the processes and results of mathematical thinking, a lectureship under the auspices of the Society was established and named after a deceased member, Josiah Willard Gibbs, who ranks among the foremost of American scientists. The series has been inaugurated by three distinguished members of the Society who in successive years have delivered lectures: M. I. Pupin on Coordination, Robert Henderson on Life insurance as a social service and as a mathematical problem, and James Pierpont on Some modern views of space.

Research Fellowships. While the Society was not in any way responsible for the extension of the plan of the National Research Fellowships in physics and chemistry so as to include mathematics also, the President of the Society in 1924 was instrumental in bringing the matter to the attention of the Rockefeller Foundation and the National Research Council. One hundred twenty-five thousand dollars annually is available for fellowships in mathematics, physics, and chemistry which should exercise a potent influence in confirming our young men and women in habits of research.

There are in addition universities and other general foundations which provide fellowships of ample size open to mathematicians for study at home or abroad.

Revolving Book Fund. Another item which is of mathematical interest, but which has no official connection with the Society, concerns a small sum appropriated by the $\mathrm{Na}$ tional Research Council for the launching of a series of treatises in mathematics. Two volumes have appeared; 
from the sales it is confidently expected that further volumes can be financed.

\section{CONTACTS WITH OTHER ORGANIZATIONS}

The Society has affiliated itself with the American Association for the Advancement of Science, and is meeting more frequently with that organization. It is significant that during this period one of our members was president of that body and that the first grand prize offered for papers submitted at a meeting of the American Association for the Advancement of Science was won by a mathematician.

A reciprocal agreement has been entered into with the London Mathematical Society, by which members of each organization enjoy special privileges in the other.

Through its officers and its representatives in the National Research Council the Society has played a prominent part in the American Section of the International Mathematical Union which shared in the organization of the successful International Mathematical Congress held in Toronto in 1924. It is the concensus of opinion, however, that we should not participate in another congress until the organization is fully internationalized.

The Society has continued to cooperate cordially with the Mathematical Association of America in the arrangement of meetings and division of work. This appears to be of mutual advantage.

In considering its own problems of printing, our organization has endeavored to bear in mind the whole question of publication of American research and to cooperate with the other journals to this end.

\section{NEEDS OF MATHEMATICS}

Having succeeded in solving the most pressing of its present problems, the Society can turn its attention to others which are of the immediate or more distant future. While many desirable projects would naturally lie outside the province of the Society, its members must keep in mind 
the various needs. The Council may wish to name a committee to outline a comprehensive scheme of development in the field as a whole.

Printing. The dearth of publication in America of advanced treatises in mathematics is much to be deprecated. The money available for printing of Colloquium Lectures and the Revolving Book Fund will serve as a beginning, but as a beginning only. Publishers must by some means be convinced that it is to their interest to print such books; there is a decided opinion on the part of the Council that firms making profits on mathematical text-books should be brought to feel under obligation to invest a part in advanced treatises.

The time is not far distant when more printing space will be necessary to care for the output of American research. Whether this will take the form of a new journal (possibly of applied mathematics) or an increase in the number of volumes of the Transactions, it is yet too early to determine.

At various times in the past the Council has considered other printing projects, such as the founding of an Abstract Journal, and has given tentative approval, provided men and money were available. The publication of extensive surveys of particular fields, encyclopedic in character, seems also highly desirable. Other projects proposed include an English edition of the encyclopedia and a mathematical dictionary.

Mathematical Institute. Some American mathematicians have conceived the idea of a Mathematical Institute, similar to those in certain foreign countries, serving as a center for mathematical research. The influence of such a body might well raise the whole level of our production; for it would not only release some of our ablest scientists for production of research, but it would also set a standard for the universities to follow. Such a project would involve large sums of money, but a well-considered plan is bound to prove of interest to those who have wealth to invest in science. 
Connected with the Institute there might grow up a summer colony in some location good at that season, where short series of lectures could be given and where there would be facilities for scientific work and personal contact with colleagues as well as for out-door recreation.

Our Own House. We are very fortunate in having office space and other facilities donated by Columbia University. The time may come, however, when some benefactor will make it possible for the Society to have quarters of its own.

\section{WHAT MEMBERS CAN DO TO ASSIST}

Having solved some of the problems confronting us we can set ourselves to attacking others. The most important part that members can play is of course production of new mathematics and the encouragement of others to do likewise. But there are other essential services which can be rendered.

Some might find it possible to transfer from ordinary to sustaining membership; others might induce their universities to assume such membership. Universities who thus subsidize our Transactions and Colloquium Lectures aid in providing outlets for the publication of the output of their staff and at a cost less than that of financing a journal of their own. Professor Fort as chairman of the new committee to conserve and extend the sustaining memberships must have the support of all members.

Other members have friends who might be interested in giving financial aid to important projects of our organization. The work of a scientific body so distinguished as the Society may make an appeal to the imagination of some benefactor.

A more modest contribution would be to aid in adding to the ordinary membership colleagues, students (present and past), and other friends of the cause.

The number of subscribers for the Transactions among the membership is rather small and might well be increased. The number of Life Members could well be augmented also. 
A few members have made provision for the Society in their wills by taking out insurance policies; this practice might become widespread. Members can also serve the organization by keeping in mind its problems and sending to the Council suggestions for meeting needs of the Society and for making improvements.

\section{PROSPECTS}

To many members the transfer of the printing back to America will be welcomed as a return to normal conditions.

One important result of the campaign for endowment is the increased recognition of the value of mathematics on the part of other groups of scientists and of the scientific industries, an attitude which needs constant cultivation. This aspect of the work of the Society seems to the Secretary much more important for the furtherance of its endeavors than is generally recognized.

The spirit of cooperation between groups in various parts of the country is most encouraging. The Society is striving to think always nationally and to serve all the interests basal to our science.

There is every reason to have faith in our future. Not only is there developing splendid material among the young men, but America possesses the wealth to make mathematical research possible in ever increasing volume. The next fiveyear period is bound to see some remarkable developments in projects for scientific research; it is the duty of those mathematicians who have vision to be prepared to seize the opportunities as they arise.

The Society stands for the highest scientific ideals and commands our loyalty and devotion. Through it we can make our impress on the history of America. As an organization should it not stand among the very foremost of those to which we as individuals devote our energies?

Respectfully submitted, R. G. D. RichaRdSON,

January 1,1926 Secretary 